\title{
Amphiphilic Statistical Copolymers from Catalytic Chain Transfer as Reactive Surfactants in Emulsion Polymerization
}

\section{Citation for published version (APA):}

Schreur-Piet, I., \& Heuts, J. P. A. (2021). Amphiphilic Statistical Copolymers from Catalytic Chain Transfer as Reactive Surfactants in Emulsion Polymerization. ACS Applied Polymer Materials, 3(9), 4616-4624. https://doi.org/10.1021/acsapm.1c00715

\section{Document license:}

CC BY-NC-ND

DOI:

10.1021/acsapm.1c00715

Document status and date:

Published: 05/08/2021

\section{Document Version:}

Publisher's PDF, also known as Version of Record (includes final page, issue and volume numbers)

\section{Please check the document version of this publication:}

- A submitted manuscript is the version of the article upon submission and before peer-review. There can be important differences between the submitted version and the official published version of record. People interested in the research are advised to contact the author for the final version of the publication, or visit the $\mathrm{DOI}$ to the publisher's website.

- The final author version and the galley proof are versions of the publication after peer review.

- The final published version features the final layout of the paper including the volume, issue and page numbers.

Link to publication

\section{General rights}

Copyright and moral rights for the publications made accessible in the public portal are retained by the authors and/or other copyright owners and it is a condition of accessing publications that users recognise and abide by the legal requirements associated with these rights.

- Users may download and print one copy of any publication from the public portal for the purpose of private study or research.

- You may not further distribute the material or use it for any profit-making activity or commercial gain

- You may freely distribute the URL identifying the publication in the public portal.

If the publication is distributed under the terms of Article 25fa of the Dutch Copyright Act, indicated by the "Taverne" license above, please follow below link for the End User Agreement:

www.tue.nl/taverne

Take down policy

If you believe that this document breaches copyright please contact us at:

openaccess@tue.nl

providing details and we will investigate your claim. 


\title{
Amphiphilic Statistical Copolymers from Catalytic Chain Transfer as Reactive Surfactants in Emulsion Polymerization
}

\author{
Ingeborg Schreur-Piet and Johan P.A. Heuts*
}

Cite This: ACS Appl. Polym. Mater. 2021, 3, 4616-4624

Read Online

ABSTRACT: Statistical copolymers of methacrylic acid (MAA) and methyl methacrylate (MMA), butyl methacrylate (BMA), or lauryl methacrylate (LMA) were synthesized via cobalt(II)mediated catalytic chain transfer polymerization (CCTP) and used as macromonomeric stabilizers in the emulsion polymerization of MMA. By varying the composition, length, and concentration of the macromonomers, we were able to tune the particle size, molar mass, and rheological behavior of the latexes. Most latexes stabilized with macromonomers containing BMA and LMA showed rheological properties such as small yield stress and shear thinning behavior similar to those of binders for coating applications.

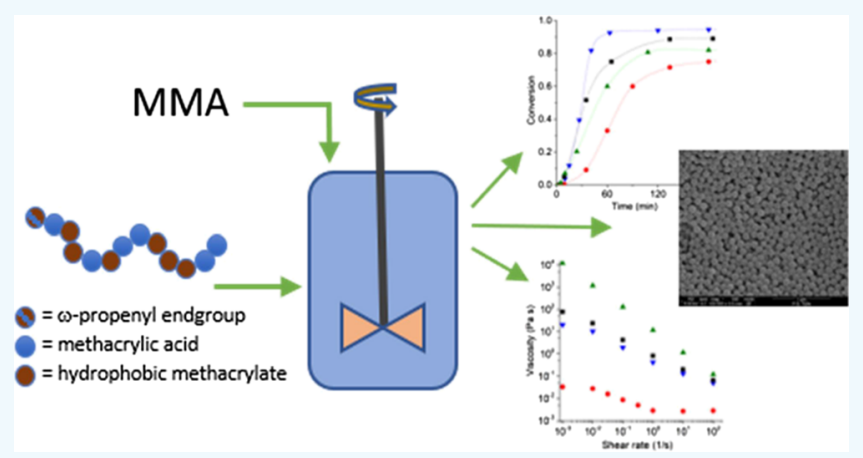

KEYWORDS: emulsion polymerization, reactive surfactant, methacrylic acid, copolymerization, macromonomer, catalytic chain transfer

\section{INTRODUCTION}

Functional polymer latexes produced by emulsion polymerization have found applications in many fields, including waterborne coatings, printing ink, adhesives, and medical applications. $^{1-4}$ Surfactants play an important role in this process. They not only control the colloidal stability of the particles in the latex, but the type and architecture of the used surfactant also have a large influence on the physical and rheological properties of the latex and thus on the final application. $^{5-7}$ In most cases, surfactants are not covalently bound to the colloidal particles; therefore, surfactants can desorb over time. Furthermore, during film formation, surfactants can migrate from the colloidal particles toward the film surface and have a negative effect on film properties such as adhesion strength, peel strength, water resistance, gloss, and blocking. ${ }^{8-15}$ To circumvent these negative effects, reactive surfactants that are chemically bound to the polymer particles can be used. ${ }^{16-21}$ An ideal reactive surfactant should not be too reactive at the start of the emulsion polymerization, in order to avoid the chemically bound surfactant molecules from being buried inside the latex particles, but at the end of the emulsion polymerization, all surfactants should have reacted to obtain a stable latex. ${ }^{22-24}$ Reactive surfactants containing a propenyl end-group are promising candidates displaying the right reactivity, and methacrylic oligomers containing these end-groups (called macromonomers in the remainder of this paper) are readily prepared via catalytic chain transfer polymerization (CCTP), 25,26 and their subsequent copolymerization behavior has been subscribed previously. $^{27-32}$ In earlier studies, amphiphilic macromonomers were synthesized and subsequently used as stabilizers in an emulsion polymerization. ${ }^{33-35}$ In our earlier work, methacrylic acid (MAA) macromonomers were synthesized via CCTP and were used directly in an emulsion polymerization to form in situ amphiphilic copolymers, ${ }^{30}$ in a mechanism similar to what is commonly known as polymerization-induced self-assembly. ${ }^{36-40}$ Only in the cases where the MAA macromonomers were sufficiently fast converted into amphiphilic copolymers, stable latexes could be produced. In another study, a two-step copolymerization of MAA macromonomers with methyl methacrylate (MMA) or butyl acrylate (BA) gave amphiphilic stabilizers suitable for the emulsion polymerization with MMA, albeit the rheology and physical properties of the systems were rather different. ${ }^{41}$ To combine the simplicity of a one-pot system, with the good results for a more hydrophobic, amphiphilic stabilizer, in the current study, $t$-butyl methacrylate ( $t$-BMA) is copolymerized statistically with MMA, butyl methacrylate (BMA), or lauryl methacrylate (LMA) via CCTP. These macromonomers were subsequently subjected to acidolysis of the t-butyl groups and used as reactive surfactants (macromonomers) in the emulsion polymerization of MMA. The physical and rheological properties of the obtained latexes are discussed in the final part of this paper.

Received: June 15, 2021

Accepted: July 29, 2021

Published: August 5, 2021 


\section{EXPERIMENTAL SECTION}

Materials. All monomers MMA, BMA, LMA, and t-BMA were obtained from Sigma-Aldrich (99\%). The monomers were passed over a column of inhibitor remover (Sigma-Aldrich) to remove the inhibitor. Azobis(isobutyronitrile) (AIBN, Merck) was recrystallized from methanol. The bismethanol complex of bis[(difluoroboryl)dimethyl glyoximato]cobalt(II) (COBF) was prepared as described previously $^{42}\left(C_{\mathrm{T}}\right.$ for MMA in bulk $=34 \times 10^{3}$ at $\left.60{ }^{\circ} \mathrm{C}\right)$. Toluene (AR, Biosolve), dichloromethane (DCM, AR, Biosolve), and trifluoro acetic acid (TFA, 95\%, Sigma-Aldrich) were used as received. Potassium persulfate (p.a.) and sodium carbonate (dehydrated, p.a.) were purchased from Merck and used as received.

General Procedure for the Synthesis of Macromonomers. To obtain statistical $t$-butyl methacrylate comacromonomers ( $t$-BMAco-RMA), a mixture of $t$-BMA and one of the comonomers, MMA, BMA, or LMA, was copolymerized with AIBN in toluene in a roundbottom flask at $60{ }^{\circ} \mathrm{C} .^{30,43}$ The comonomer was added in two different amounts to obtain comacromonomers with 10 and $30 \mathrm{~mol} \%$ of the comonomer, respectively. Also, the initially added amount of the COBF catalyst was varied to obtain macromonomers with different molar masses. The macromonomers were subsequently treated to trifluoroacetic acid to yield the corresponding $\mathrm{MAA}_{n}$-co$\mathrm{RMA}_{m}$ amphiphilic macromonomer stabilizers.

As a typical example of the procedure followed, we report here the synthesis of $\mathrm{MAA}_{202}-\mathrm{co}-\mathrm{BMA}_{22}$ macromonomers; for the exact quantities used for all other macromonomers, we refer to the Supporting Information. First, $44 \mathrm{~g}$ of $t$-BMA $(0.31 \mathrm{~mol}), 5.1 \mathrm{~g}$ of BMA $(0.036 \mathrm{~mol})$, and $96 \mathrm{~g}$ of toluene were added to a $100 \mathrm{~mL}$ round-bottom flask (solution A). The flask was sealed airtight with a septum, and the mixture was deoxygenated by purging with nitrogen in an ice bath for $30 \mathrm{~min}$. Simultaneously, $200 \mathrm{mg}$ of AIBN (1.2 $\mathrm{mmol})$ and $1.9 \mathrm{mg}$ of $\mathrm{COBF}\left(4.9 \times 10^{-6} \mathrm{~mol}\right)$ were added to a separate $100 \mathrm{~mL}$ round-bottom flask (B) containing a magnetic stirrer bar. The flask was consecutively evacuated and purged with nitrogen three times. Subsequently, the monomer solution A was added to flask $\mathrm{B}$, heated to $60{ }^{\circ} \mathrm{C}$, and left to react for $16 \mathrm{~h}$ under continuous stirring. The obtained statistical $t$-BMA-co-BMA macromonomer was isolated by evaporation of toluene and the residual monomer under reduced pressure and dried in a vacuum oven at $60{ }^{\circ} \mathrm{C}$ for $24 \mathrm{~h}$ (overall yield $90 \%$ ). Subsequently, $40 \mathrm{~g}$ of $t$-BMA-co-BMA macromonomer was added to a $100 \mathrm{~mL}$ round-bottom flask containing 80 $\mathrm{mL}$ of dichloromethane and stirred at room temperature until the polymer dissolved completely, after which $40 \mathrm{~mL}$ of trifluoroacetic acid $(0.52 \mathrm{~mol})$ was added and stirred at room temperature for $48 \mathrm{~h}$. Dichloromethane and excess trifluoroacetic acid were removed by evaporation under reduced pressure, and the resulting $\mathrm{MAA}_{202}-\mathrm{co}$ $\mathrm{BMA}_{22}$ macromonomer was dried in a vacuum oven at $60{ }^{\circ} \mathrm{C}$ for 2 days (quantitative yield). The number average degree of polymerization, $\mathrm{DP}_{\mathrm{n}}$, and the dispersity, $Ð$, were determined by ${ }^{1} \mathrm{H} \mathrm{NMR}$ and SEC. The critical micelle concentration (CMC) of these amphiphilic macromonomers was determined by dynamic light scattering (DLS).

Emulsion Polymerization. Emulsion polymerizations were carried out in batch. All experiments were carried out under argon in a jacketed glass reactor $(250 \mathrm{~mL})$, thermostated at $60{ }^{\circ} \mathrm{C}$, and equipped with a mechanical four-bladed turbine stirrer. The monomer conversions during the reaction were determined gravimetrically. First, all ingredients except for the initiator solution were charged into the reactor, and the reaction mixture was stirred at $350 \mathrm{rpm}$, purged with argon for $30 \mathrm{~min}$, and subsequently heated to $60{ }^{\circ} \mathrm{C}$. Five minutes after reaching the desired temperature, the aqueous KPS solution was added via a syringe to initiate the polymerization (for composition see Table 1).

Analysis. Nuclear Magnetic Resonance. ${ }^{1} \mathrm{H}$ NMR spectra were recorded on a Varian MercuryVx spectrometer at $400 \mathrm{MHz}$. Chloroform- $d_{1}$, methanol- $d_{4}$, DMSO- $d_{6}$, THF- $d_{8}$, and tetramethylsilane were used as solvents and the internal standard, respectively.

Scanning Electron Microscopy. SEM analyses were performed with an FEI Quanta 3D FEG (ETD; $5 \mathrm{kV}$; spot size 4.5). All samples were sputter coated with $10 \mathrm{~nm}$ gold before imaging.
Table 1. Recipe of a Batch Emulsion Polymerization at $T=$ $60{ }^{\circ} \mathrm{C}$ and $\mathrm{pH}=10$

\begin{tabular}{ll}
\multicolumn{1}{c}{ ingredient } & \multicolumn{1}{c}{ amount } \\
water & $80 \mathrm{~g} \quad 0.3 \mathrm{~g}\left(2 \cdot 10^{-2} \mathrm{M}\right)$ \\
$\mathrm{Na}_{2} \mathrm{CO}_{3}$ & variable; $1 \mathrm{~g}\left(5 \mathrm{wt} \%^{a}\right)$ is the standard level \\
macromonomer & $20 \mathrm{~g}($ solid content $\approx 20 \%)$ \\
monomer MMA & $0.05 \mathrm{~g}\left(0.25\right.$ wt $\left.\%^{a} ; 2.3 \times 10^{-3} \mathrm{M}\right)$ \\
$\mathrm{K}_{2} \mathrm{~S}_{2} \mathrm{O}_{8}(\mathrm{KPS})$ &
\end{tabular}

$a_{\text {wt }} \%=$ weight percentage relative to the monomer $(=\mathrm{g} / 100 \mathrm{~g}$ of monomer).

MALDI-ToF MS. MALDI-ToF MS spectra were recorded on a PerSeptive Biosystems Voyager-DE STR MALDI-ToF MS spectrometer equipped with $2 \mathrm{~m}$ flight tubes for linear mode and $3 \mathrm{~m}$ flight tubes for reflector mode and a $337 \mathrm{~nm}$ nitrogen laser ( $3 \mathrm{~ns}$ pulse). All mass spectra were obtained with an accelerating potential of $20 \mathrm{kV}$ in positive ion and reflector mode with delayed extraction. Data were processed with Voyager software. Simulations were performed with the MALDI Analysis software by Staal and Willemse. ${ }^{44,45}$ The MAAcontaining polymer samples were dissolved in methanol, the other polymer samples were dissolved in THF at solvent concentrations of 5 $\mathrm{mg} / \mathrm{mL}$. 2,4,6-Trihydroxyacetophenone $(80 \mathrm{mg} / \mathrm{mL}$ THF or methanol) was used as the matrix, and diammonium hydrogen citrate $(5 \mathrm{mg} / \mathrm{mL}$ THF or methanol) as the cationating agent. Analyte solutions were prepared by mixing the matrix, salt, and polymer at a 4:1:4 volume ratio. Subsequently, $0.30 \mu \mathrm{L}$ of this mixture was spotted on the sample plate, and the spots were dried at room temperature.

Dynamic Light Scattering (DLS). DLS analyses were performed with a Nanotrac Ultra (Microtrac systems). The used laser is a gallium-aluminum-arsenide semiconductor diode laser with a wavelength of $780 \mathrm{~nm}$ and a power of $3-5 \mathrm{~mW}$. The angle of incident-to-scattered light is $180^{\circ}$ (backscatter). This technique uses the Brownian motion of the molecules. The cumulant algorithm was used to obtain the particle size distribution from the second-order autocorrelation function. The mean diameter was evaluated from the Stokes-Einstein equation for spheres (according to International standard ISO22412 and ISO13321).46,47

Size Exclusion Chromatography (SEC). SEC was carried out using a Waters Alliance system equipped with a Waters 2695 separation module, a Waters 2414 refractive index detector $\left(40{ }^{\circ} \mathrm{C}\right)$, a Waters 2487 dual UV absorbance detector, and a PSS SDV $5 \mu \mathrm{m}$ bead size guard column followed by two PSS SDV $5 \mu \mathrm{m}$ bead size linearXL columns in series $(300 \times 8 \mathrm{~mm})$ at $40{ }^{\circ} \mathrm{C}$. Tetrahydrofuran (THF stabilized with BHT, Biosolve) with $1 \mathrm{v} / \mathrm{v}-\%$ acetic acid was used as the eluent at a flow rate of $1.0 \mathrm{~mL} \mathrm{~min}{ }^{-1}$. The system was calibrated with polystyrene standards.

Zeta Potential Analysis. Zeta potential analyses were performed using a Zetasizer Nano ZS (Malvern Instruments) whereby laser doppler microelectrophoresis is used to measure the zeta potential. An electric field is applied to a highly dilute dispersion of particles, which then move with a velocity related to their zeta potential. The velocity is measured using phase analysis light scattering; the used laser is a 4 $\mathrm{mW} \mathrm{He}-\mathrm{Ne}$ laser with a wavelength of $633 \mathrm{~nm}$.

CMC Measurements. DLS experiments were performed with a AntonPaar Litesizer 500. The used laser is a $40 \mathrm{~mW}$ laser with a wavelength of $658 \mathrm{~nm}$. The CMC was determined from the intensity of the scattered light as a function of the concentration of the macromonomer. All macromonomers were dissolved in and diluted with an aqueous solution of $\mathrm{Na}_{2} \mathrm{CO}_{3}\left(4 \times 10^{-2} \mathrm{M}\right)$.

Rheology. Rheological measurements were performed at $20{ }^{\circ} \mathrm{C}$ using an Anton Paar Physica MCR 301 rheometer with a concentric cylinder CC27 system (inner and outer diameters are 26.66 and 28.92 $\mathrm{mm}$, respectively) in the auto optimization mode using the Smoluchowski model. In order to get a more quantitative insight into the appearances and the rheological properties of the prepared latexes, we measured the viscosities as a function of the shear rate between 0.001 and $100 \mathrm{~s}^{-1}$; for each measurement point, the shear rate was kept constant until the viscosity reached a steady value. We 
Table 2. Characteristics of Statistical Comacromonomer Stabilizers ${ }^{a}$

\begin{tabular}{|c|c|c|c|c|c|c|c|c|}
\hline$\#^{b}$ & $F_{M}^{c}$ & $\mathrm{DP}_{\mathrm{n}}^{d}$ & $n \mathrm{MAA}^{e}$ & $m \mathrm{RMA}^{e}$ & $\bigoplus^{f}$ & wt $\% \mathrm{RMA}^{g}$ & wt $\% \mathrm{R}^{g}$ & $\mathrm{CMC}^{h}(\mathrm{mM})$ \\
\hline $\mathrm{B}_{448-51}$ & 0.10 & 499 & 448 & 51 & 2.0 & 0.16 & 0.06 & $6.3 \times 10^{-4}$ \\
\hline $\mathrm{B}_{202-22}$ & 0.10 & 224 & 202 & 22 & 2.5 & 0.15 & 0.06 & $7.7 \times 10^{-3}$ \\
\hline $\mathrm{B}_{80-23}$ & 0.22 & 103 & 80 & 23 & 6.3 & 0.32 & 0.13 & $1.1 \times 10^{-2}$ \\
\hline $\mathrm{B}_{3-1}$ & 0.30 & 4.7 & 3.3 & 1.4 & 1.4 & 0.41 & 0.17 & $1.9 \times 10^{-1}$ \\
\hline $\mathrm{L}_{204-18}$ & 0.08 & 222 & 204 & 18 & 3.5 & 0.21 & 0.14 & $3.4 \times 10^{-3}$ \\
\hline $\mathrm{L}_{189-21}$ & 0.10 & 210 & 189 & 21 & 3.0 & 0.25 & 0.16 & $4.2 \times 10^{-3}$ \\
\hline $\mathrm{L}_{15-2}$ & 0.09 & 17 & 15 & 1.5 & 2.5 & 0.23 & 0.15 & $6.9 \times 10^{-3}$ \\
\hline $\mathrm{L}_{8-3}$ & 0.28 & 12 & 8.4 & 3.2 & 1.7 & 0.53 & 0.35 & $6.5 \times 10^{-2}$ \\
\hline $\mathrm{L}_{5-1}$ & 0.10 & 5.0 & 4.5 & 0.5 & 1.3 & 0.25 & 0.16 & $7.6 \times 10^{-1}$ \\
\hline
\end{tabular}

${ }^{a}$ Macromonomers of $\mathrm{MAA}_{n}-c o-\mathrm{RMA}_{m}$ synthesized from $t-\mathrm{BMA}_{n}-c o-\mathrm{RMA}_{m}$ macromonomers; $\mathrm{R}$ is butyl or lauryl. ${ }^{b}$ Notation: $\mathrm{R}_{n-m}$ : $\mathrm{B}$ " = MAA ${ }_{n}$-co$\mathrm{BMA}_{m}$ or "L" = $\mathrm{MAA}_{n}-c o-\mathrm{LMA}_{m}$ and subscript $n-m$ indicates the number of monomer units of both monomers. ${ }^{c} F_{\mathrm{M}}=$ mol fraction of the comonomer in the macromonomer estimated from ${ }^{1} \mathrm{H}$ NMR, standard error ca. $5 \% .{ }^{d}$ Number average degree of polymerization estimated from ${ }^{1} \mathrm{H}$ NMR. ${ }^{e}$ Mean DP ${ }_{n}$ for MAA and RMA units resp. ${ }^{f}$ Dispersity of the $t$-BMA-comacromonomer determined via SEC. ${ }^{g}$ Weight percentage of RMA and $\mathrm{R}$ units in the macromonomer resp. ${ }^{h}$ Critical micelle concentration determined via DLS.

also probed the mechanical microstructure by measuring the dynamic moduli G' and G' for a period of $1000 \mathrm{~s}$ at a fixed frequency (i.e., a dynamic time sweep). In order to check the recoverability of the structure after such time sweep, the sample was agitated (using a shear rate of $100 \mathrm{~s}^{-1}$ for a duration of $100 \mathrm{~s}$ ), after which another dynamic time sweep was recorded. The linear viscoelastic region was determined by performing a strain sweep experiment at an angular frequency of $6.3 \mathrm{rad} \cdot \mathrm{s}^{-1}$. A stress of $0.001 \mathrm{~Pa}$ was chosen because this stress was sufficiently high to effectively suppress noise and small enough to stay in the linear region.

\section{RESULTS AND DISCUSSION}

After synthesis, the MAA-containing comacromonomers were characterized and used as stabilizers in the batch emulsion polymerization of MMA. The kinetics of the polymerization were followed, and the particle diameters, the zeta potentials, and the rheological behavior of the latexes were determined. Except for the polymerization with $\mathrm{MAA}_{10}$ co- $\mathrm{MMA}_{4}$, all emulsion polymerizations with $\mathrm{MAA}_{n}$-co-MMA $m$ gave extensive coagulation in an early stage of the reaction; no conversions higher than $20 \%$ could be achieved. It is conceivable that these macromonomers are too hydrophilic and that they are not converted sufficiently fast into truly surface-active molecules by the addition-fragmentation chain transfer polymerization with MMA, similar to what we previously observed using homo $\mathrm{MAA}_{n}$ macromonomers. ${ }^{30}$

In the remainder of this paper, we therefore limit ourselves to the discussion of the BMA- and LMA-based macromonomers and refer to the Supporting Information for the results of the MMA-based macromonomers. It should be noted here that although the systems are not completely comparable, Shegiwal et al. ${ }^{32}$ also encountered problems in the emulsion polymerization with MMA-containing macromonomers with high acid concentration; for example, macromonomers containing 35 wt \% MAA and 65 wt \% MMA gave coagulation and large particle sizes $(>200 \mathrm{~nm})$. Although this result was not discussed further by the authors, they suggest in a later publication $^{35}$ that increasing the polymerization temperature to $75{ }^{\circ} \mathrm{C}$ or higher results in more stable latexes, presumably because of higher initiator decomposition rates and increasing monomer solubility in the aqueous phase.

To facilitate the further discussion, we categorize the latexes according to visual appearance into three types: type $I$ is a colloidally stable, liquid-like latex (low viscosity, containing no visible sediment/coagulum), type II is a (weakly) flocculated latex, which may contain some redispersible sediment, and type III is a highly viscous latex with a strong internal network structure (gelated). ${ }^{41}$

Characterization of Macromonomers by ${ }^{1} \mathrm{H}$ NMR and MALDI-ToF MS. The macromonomer compositions before and after acidolysis were determined by ${ }^{1} \mathrm{H}$ NMR and MALDIToF MS. By ${ }^{1} \mathrm{H}$ NMR, the mole fractions of both monomer units were determined from the intensity of the signals of the methyl group bound to the ester group relative to those of the propenyl end group and the rest of the peaks. By MALDI-ToF MS, the exact masses of the macromonomers were determined; these masses were consistent with the two characteristic end groups, a hydrogen atom at the $\alpha$-chain end and a vinyl group at their $\omega$-terminal. Hence, both the NMR and MALDI results confirm that all obtained polymers are indeed MAA macromonomers (for more details of the NMR spectra, calculations of $\mathrm{DP}_{\mathrm{n}}$, and a MALDI-ToF MS spectrum with a table containing the assignments of the peaks, see the Supporting Information).

SEC analyses were performed for the $t-\mathrm{BMA}_{n}-\mathrm{co}-\mathrm{RMA}_{m}$ macromonomers to determine the dispersity $(\boxplus)$ of all macromonomers. $D$ was assumed to be the same after acidolysis of the $t$-BMA group to MAA. Most macromonomers have $Ð \approx 2-3$, except for $\mathrm{B}_{80-23}$ and $\mathrm{L}_{82-26}$, which have $\boxplus \approx$ 6.5. The CMC decreases with increasing $D P_{n}$ of the macromonomer for both BMA- and LMA-comacromonomers. These CMCs are all lower than the used surfactant concentration in all cases. No relation was found between the length of hydrophobic block (BMA versus LMA) or the wt $\%$ of the hydrophobic block in the macromonomer (wt \% R) and the CMC. A summary of the characteristics of $\mathrm{MAA}_{n}-\mathrm{co}$ $\mathrm{BMA}_{m}$ and $\mathrm{MAA}_{n}-\mathrm{co}-\mathrm{LMA}_{m}$ comacromonomers is given in Table 2.

Emulsion Polymerization. Using the synthesized $\mathrm{MAA}_{n}$ co- $\mathrm{BMA}_{m}$ and $\mathrm{MAA}_{n}$-co-LMA $m$ macromonomers, stable latexes were obtained in most cases. The nomenclature of the latexes is as follows: $x \mathrm{~L}-\mathrm{R}_{n-m}$, where $x$ is the added wt $\%$ of the macromonomer, $\mathrm{L}$ for latex, and $\mathrm{R}_{n-m}$ is the macromonomer mentioned in Table 2. For example, $5 \mathrm{~L}-\mathrm{B}_{3-1}$ means that in this latex, 5 wt $\%$ of macromonomer $\mathrm{B}_{3-1}$ was used as the surfactant.

Emulsion Polymerization Using $\mathrm{MAA}_{n}-\mathrm{Co}-\mathrm{BMA}_{m}$ Macromonomers. The appearance of all latexes stabilized by $\mathrm{MAA}_{n}-\mathrm{co}-\mathrm{BMA}_{m}$ was of type II: all latexes were flocculated and 
showed a high viscosity at rest. In Figure 1, the conversion vs time curves for a series of emulsion polymerizations stabilized

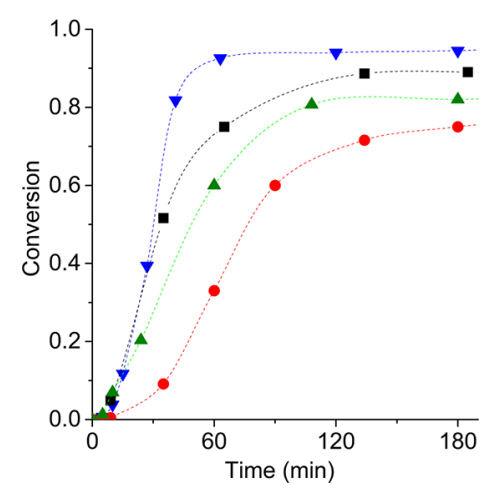

Figure 1. Emulsion polymerization of MMA stabilized with 5 wt \% $\mathrm{MAA}_{n}-\mathrm{co}-\mathrm{BMA}_{m}$ macromonomer, according to the standard recipe (Table 1). (blue solid inverted triangle) $5 \mathrm{~L}-\mathrm{B}_{448-51}$; (green solid

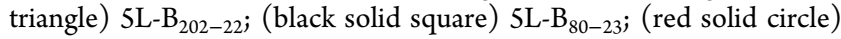
$5 \mathrm{~L}-\mathrm{B}_{3-1}$. Finally, all reactions reach around $100 \%$ conversion. The lines in the graph are only to guide the eye.

by 5 wt $\%$ of different $\mathrm{MAA}_{n}$-co-BMA $m$ macromonomers are shown, and it is clear that all reactions show typical emulsion polymerization behavior. Although the molar concentration of the macromonomer surfactant $([\mathrm{MM}])$ increases by a factor of 100 , the differences in polymerization rates between the four reactions are not very large and actually contrary to what would be expected (the reaction using $\mathrm{B}_{448-51}$ as the stabilizer being the fastest and using $\mathrm{B}_{3-1}$ the slowest (see Table 3 and the Supporting Information)).

The system stabilized by $\mathrm{B}_{3-1}$ shows an initial delay in the onset of polymerization, suggesting that the particle nucleation is slower; first, the addition of some hydrophobic MMA units is needed before large enough micelles are formed suitable for nucleation. The low number-average molar mass of this latex $\left(M_{\mathrm{n}}=55 \mathrm{~kg} \mathrm{~mol}^{-1}\right)$ is the result of chain transfer because these macromonomeric surfactants act as chain transfer agents (they are so-called transurfs). ${ }^{18,20,25-29}$ The other three latexes show a higher molar mass because of the lower [MM] used to prepare these latexes, giving less chain transfer.

On comparing the zeta potentials $(\zeta)$ of these latexes, it can be seen that the first three latexes are characterized by $\zeta \approx-45$ $\mathrm{mV}$ and the latex stabilized by $\mathrm{B}_{3-1}$ is characterized by $\zeta \approx-28$ $\mathrm{mV}$. Although this latter system has the highest [MM] (22 $\mathrm{mM})$, it has the lowest concentration of MAA units [MAA] $(73 \mathrm{mM})$, resulting in less electrostatic repulsion by MAA units on the particle surface and therefore a lower zeta potential. For the other latexes, the stabilization of the particles is caused by both electrostatic repulsion and interchain repulsion forces caused by the longer polymeric chains. ${ }^{48}$ The extent of network formation in these latexes due to these longer polymer chains will increase the viscosity and reduce the mobility of the chains. This is consistent with a type II latex: a high viscosity at rest but with a low viscosity when shaken.

In order to get a more quantitative insight into the appearances and the rheological properties of the prepared latexes, we measured the viscosities as a function of the shear rate and probed the mechanical microstructure by performing a dynamic time sweep measurement to determine the dynamic moduli G' and G' as a function of time. In Figure 2, these results are shown.

In Figure 2a, a comparison of the flow curves (viscosity versus shear rate) is made for all latexes. All latexes show shear thinning behavior, with a high viscosity at low shear rates $\left(\eta_{0}\right)$ and low viscosity at high shear rates $\left(\eta_{\infty}\right)$. The viscosities of most of the latexes do not level off at high shear rates, suggesting that even higher shear rates are needed to break up the internal network structure. ${ }^{7,48}$ The exception is latex 5L$B_{3-1}$, which levels off above a shear rate of $10 \mathrm{~s}^{-1}$ and at a low viscosity level. The slopes of the curves in the double-log plot are between -0.5 and -1 , which is indicative of (pseudo-) plastic behavior; this means that large agglomerates stick to each other and form a soft solid. ${ }^{49,50}$ For the latex stabilized with $5 \mathrm{~L}-\mathrm{B}_{202-22}$, a yield stress $\left(\tau_{0}\right)$ of $12 \mathrm{~Pa}$ is determined (slope $=-1$ ), and for the other three latexes, these values are very low and estimated to lie between 0.02 and $0.08 \mathrm{~Pa}$. These results are supported by the results of the dynamic time sweep experiments (Figure $2 \mathrm{~b}$ ). In Figure $2 \mathrm{~b}$, a plot of the storage and loss moduli ( $G^{\prime}$ and $G^{\prime \prime}$, respectively) versus time of all latexes is shown. Shown are the results of two sequential time sweeps $($ duration $=1000 \mathrm{~s}, \omega=6.3 \mathrm{rad} / \mathrm{s}$, and strain $=0.001$ ). Latexes $5 \mathrm{~L}-\mathrm{B}_{202-22}$ and $5 \mathrm{~L}-\mathrm{B}_{80-23}$ behave like soft solids $\left(G^{\prime}>\right.$ $\left.\left.G^{\prime \prime}\right)\right)^{7,51}$ and the behavior is consistent with a space-filled flocculated packing where the flocs break up the bonds with their neighboring flocs when sheared but on rest immediately restore these bonds. The latexes stabilized by $\mathrm{B}_{448-51}$ and $\mathrm{B}_{3-1}$ are more fluidlike $\left(G^{\prime \prime} \geq G^{\prime}\right)$; some internal structure is built up in time, but the extent of agglomeration at rest is very limited. The G" values are $\sim 0.8$ and $0.3 \mathrm{~Pa}$, respectively, which indicates that the network formation is minor.

Emulsion Polymerization Using $\mathrm{MAA}_{n}-\mathrm{Co}-\mathrm{LMA}_{m}$ Macromonomers. A series of emulsion polymerizations stabilized by $\mathrm{MAA}_{n}$-co-LMA $m$ macromonomers was also performed. Variations in the recipes included different compositions and different concentrations of the macromonomeric surfactants. An overview of all polymerizations and the characteristics of the latexes is given in the Supporting Information.

Table 3. Characteristics of Synthesized Latexes Stabilized with 5 wt \% MAA -co-BMA $_{m}$ Macromonomers

$\begin{array}{lccccccc}\#^{a} & {[\mathrm{MM}]^{b}(\mathrm{mM})} & {[\mathrm{MAA}]^{c}(\mathrm{mM})} & D_{\mathrm{n}}{ }^{d}(\mathrm{~nm}) & \mathrm{rpp}^{e}\left(\mathrm{~m}^{3} \mathrm{~h}^{-1} / 10^{-22}\right) & \zeta^{f}(\mathrm{mV}) & M_{\mathrm{n}}^{g}\left(\mathrm{~kg} \cdot \mathrm{mol}^{-1}\right) & \Xi^{g} \\ 5 \mathrm{~L}-\mathrm{B}_{448-51} & 0.26 & 116 & 106 \pm 24 & 40 \pm 15 & -42 & 501 \\ 5 \mathrm{~L}-\mathrm{B}_{202-22} & 0.58 & 117 & 110 \pm 24 & 19 \pm 7 & -52 & 2.1 \\ 5 \mathrm{~L}-\mathrm{B}_{80-23} & 1.2 & 93 & 140 \pm 28 & 55 \pm 18 & -45 & 497 \\ 5 \mathrm{~L}-\mathrm{B}_{3-1} & 22 & 73 & 117 \pm 31 & 19 \pm 9 & -28 & 55\end{array}$

\footnotetext{
${ }^{a}$ All latexes (L) are indexed as $x \mathrm{~L}-\mathrm{B}_{n-m}$ where $\mathrm{x}$ is the added wt $\%$ macromonomer and $\mathrm{B}_{n-m}$ is the used $\mathrm{MAA}_{n}$-co-BMA $\mathrm{BMacromonomer}_{m}$ ${ }^{b}$ Concentration of the macromonomer. ${ }^{c}$ Overal concentration of MAA units determined from the used mass and the weight fraction of MAA in the macromonomer. ${ }^{d}$ Number-average diameter with $95 \%$ confidence interval (CI) determined by SEM, particle count $>100 .{ }^{e}$ Rate per particle $=$

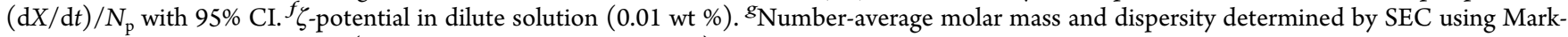
Houwink constants for pMMA (see the Supporting Information) to convert the polystyrene calibration curve.
} 

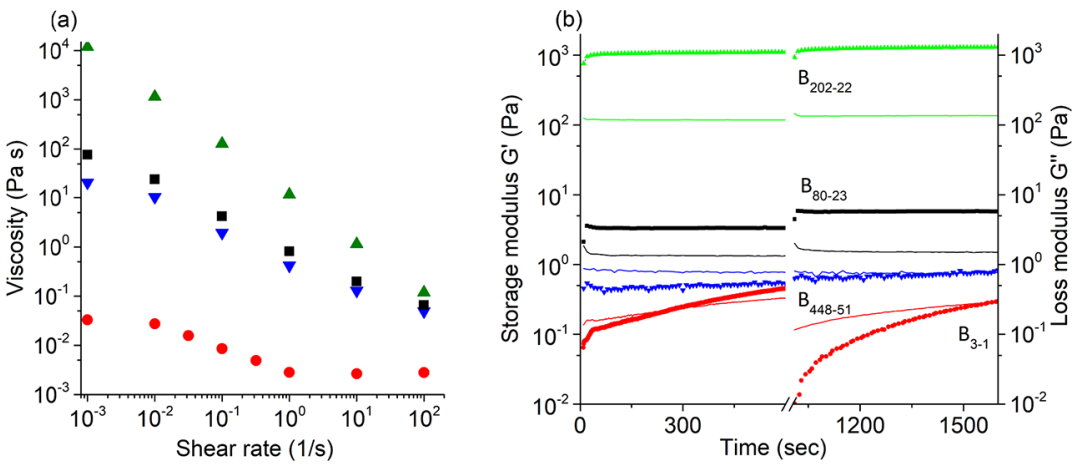

Figure 2. Rheology of the pMMA latex stabilized with 5 wt $\% \mathrm{MAA}_{n}-c o-\mathrm{BMA}_{m}$ : (a) viscosity; (b) storage modulus G' (solid line) and loss modulus G" (dotted line) as a function of time; at $1000 \mathrm{~s}$, the sample was agitated at a shear rate $100 \mathrm{~s}^{-1}$ for $100 \mathrm{~s}$; (blue solid inverted triangle) $5 \mathrm{~L}-\mathrm{B}_{448-51}$; (green solid triangle) $5 \mathrm{~L}-\mathrm{B}_{202-22}$; (black solid square) $5 \mathrm{~L}-\mathrm{B}_{80-23}$; (red solid circle) $5 \mathrm{~L}-\mathrm{B}_{3-1}$.

In Figure 3a, conversion versus time curves of a series of latexes stabilized with 5 wt $\%$ of different $\mathrm{MAA}_{n}-c o-\mathrm{LMA}_{m}$
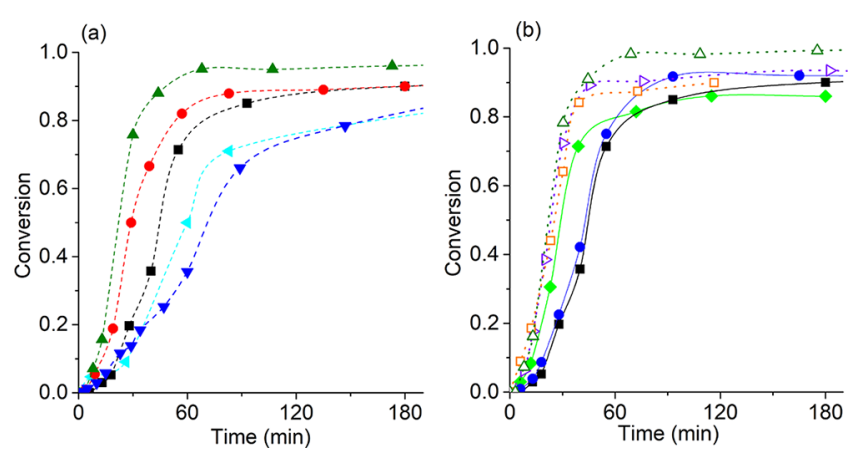

Figure 3. Conversion versus time curves for the emulsion polymerization of MMA according to the standard recipe (Table 1) (a) stabilized with 5 wt \% of $\mathrm{MAA}_{n}-\mathrm{co}-\mathrm{LMA}_{m}$ macromonomers with different compositions: (green solid triangle) $5 \mathrm{~L}-\mathrm{L}_{189-21}$; (cyan solid left-pointing triangle) $5 \mathrm{~L}-\mathrm{L}_{82-26}$; (black solid square) $5 \mathrm{~L}-\mathrm{L}_{15-2}$; (red solid circle) $5 \mathrm{~L}-\mathrm{L}_{8-3}$; (blue solid inverted triangle) $5 \mathrm{~L}-\mathrm{L}_{5-1}$; (b) stabilized with variable amounts of macromonomer: (yellow open square) $1.3 \mathrm{~L}-\mathrm{L}_{204-18}(1.3 \mathrm{wt} \%)$; (purple open right-pointing triangle) 2.5L- $\mathrm{L}_{204-18}(2.5 \mathrm{wt} \%)$; (green open triangle) $5 \mathrm{~L}-\mathrm{L}_{189-21}(5 \mathrm{wt} \%)$; (lime solid diamond) $1.3 \mathrm{~L}-\mathrm{L}_{15-2}(1.3 \mathrm{wt} \%$ ); (black solid square) 5L$\mathrm{L}_{15-2}$ (5 wt \%); (blue solid circle) $10 \mathrm{~L}-\mathrm{L}_{15-2}(10 \mathrm{wt} \%)$. The lines in the graph are only to guide the eye. macromonomers are shown. All reactions show typical emulsion polymerization behavior. With a decreasing surfactant chain length $\left(\mathrm{DP}_{\mathrm{n}}\right)$, a decrease in the particle diameter $\left(D_{\mathrm{n}}\right)$ and a decrease in the rate per particle (rpp) are observed in all cases, except for $5 \mathrm{~L}_{-1} \mathrm{~L}_{5-1}$ (see Table 4). Latex $5 \mathrm{~L}-\mathrm{L}_{5-1}$ shows a higher $D_{\mathrm{n}}$ than expected from the chain length but also has a very broad distribution. In this case, it is likely that not all macromonomers contain LMA, resulting in less efficient particle nucleation. Since not all macromonomers are amphiphilic from the start of the reaction, first the addition of some MMA units is needed before the macromonomers become surface active and are able to form micelles, which are suitable for particle nucleation. Latex $5 \mathrm{~L}_{-12-26}$ reached a conversion of $86 \%$ after $4 \mathrm{~h}$ but appeared to be colloidally unstable in time; the lack of stability is obvious from the low $\zeta$ potential of $-23 \mathrm{mV}$.

In Figure 3b, the conversion versus time curves of two series of latexes using different concentrations of macromonomer $\mathrm{L}_{15-2}$ and $\mathrm{L}_{204-18 / 189-21}$ are shown. From these curves, it can be seen that the amount of macromonomer does not have much influence on the overall polymerization rate; this has also been observed in our earlier work on macromonomeric stabilizers. ${ }^{41}$ On comparing the overall polymerization rates using the different macromonomers, it can be seen that all polymerizations using $\mathrm{L}_{189-21 / 204-18}$ proceed much faster than those with $\mathrm{L}_{15-2}$. An explanation can be that the former macromonomer, $\mathrm{L}_{189-21 / 204-18}$, is already a small particle from the start of the polymerization and acts as a "seed." This is

Table 4. Characteristics of Synthesized Latexes Stabilized with $\mathrm{MAA}_{n}$-co-LMA $\mathrm{LA}_{m}$ Macromonomers

\begin{tabular}{|c|c|c|c|c|c|c|c|}
\hline$\#$ & type $^{a}$ & {$[\mathrm{MM}]^{b}(\mathrm{mM})$} & $D_{n}{ }^{c}(\mathrm{~nm})$ & $\operatorname{rpp}^{d}\left(\mathrm{~m}^{3} \cdot \mathrm{h}^{-1} / 10^{-22}\right)$ & $\zeta^{e}(\mathrm{mV})$ & $M_{\mathrm{n}}^{f}\left(\mathrm{~kg} \mathrm{~mol}^{-1}\right)$ & $\bigoplus^{f}$ \\
\hline $5 \mathrm{~L}-\mathrm{L}_{189-21}$ & I & 0.56 & $89 \pm 35$ & $26 \pm 17$ & -46 & 441 & 4.7 \\
\hline $5 \mathrm{~L}-\mathrm{L}_{82-26}$ & II & 0.90 & $63 \pm 55$ & $5 \pm 7$ & -23 & 318 & 5.4 \\
\hline $5 \mathrm{~L}-\mathrm{L}_{15-2}$ & II & 6.9 & $57 \pm 40$ & $4 \pm 5$ & -55 & 122 & 4.3 \\
\hline $5 \mathrm{~L}-\mathrm{L}_{8-3}$ & I & 8.5 & $36 \pm 18$ & $1 \pm 1$ & -53 & 53 & 5.2 \\
\hline $5 \mathrm{~L}-\mathrm{L}_{5-1}$ & I & 23 & $64 \pm 40$ & $4 \pm 4$ & -40 & 40 & 5.9 \\
\hline $1.3 \mathrm{~L}-\mathrm{L}_{15-2}$ & II & 1.7 & $78 \pm 44$ & $14 \pm 14$ & -48 & 300 & 5.8 \\
\hline $10 \mathrm{~L}-\mathrm{L}_{15-2}$ & I & 14 & $62 \pm 30$ & $6 \pm 5$ & -52 & 68 & 4.0 \\
\hline $1.3 \mathrm{~L}-\mathrm{L}_{204-18}$ & II & 0.14 & $120 \pm 30$ & $71 \pm 30$ & -49 & 876 & 2.8 \\
\hline $2.7 \mathrm{~L}-\mathrm{L}_{204-18}$ & I & 0.35 & $96 \pm 24$ & $37 \pm 16$ & -51 & 449 & 1.9 \\
\hline
\end{tabular}

${ }^{a}$ Appearance of latex: I: fluidic, II: viscous latex with reversible flocculation. ${ }^{41}{ }^{b}$ Concentration of the macromonomer, determined from the used mass and added weight fraction. ${ }^{c}$ Number-average diameter with $95 \%$ confidence interval (CI) determined by SEM, particle count $\approx 100 .{ }^{d}$ Rate per particle $=(\mathrm{d} X / \mathrm{d} t) / N_{\mathrm{p}}$ with $95 \%$ CI determined in interval II. ${ }^{\ell} \zeta$-potential in dilute solution $(0.01$ wt $\%) .{ }^{f_{\text {Number-average molar mass and }}}$ dispersity determined by SEC using Mark-Houwink constants for pMMA (see the Supporting Information) to convert the polystyrene calibration curve. 
different from the conversion versus time curves of the polymerizations using $\mathrm{L}_{15-2}$, which show a nucleation period at the start of the polymerization; these macromonomers are probably partly dissolved in the water phase and do not form micelles so quickly. The, for conventional emulsion polymerization, ${ }^{3}$ expected decrease in $D_{\mathrm{n}}$ with an increase of [MM] can only be found for the large, amphiphilic macromonomer: $\mathrm{L}_{204-18 / 189-21}$. It appears that an amount of only $1.3 \mathrm{wt} \%$ of this macromonomer is already enough to perform an emulsion polymerization resulting in a stable latex. Although the particle size distribution of the latexes is rather broad, it is clear that the rpp decreases with a decrease in $D_{\mathrm{n}}$ (Figure $4 \mathrm{a}$ ). The observed decrease in the rpp is consistent with increasing exit and termination rates. ${ }^{52,53}$
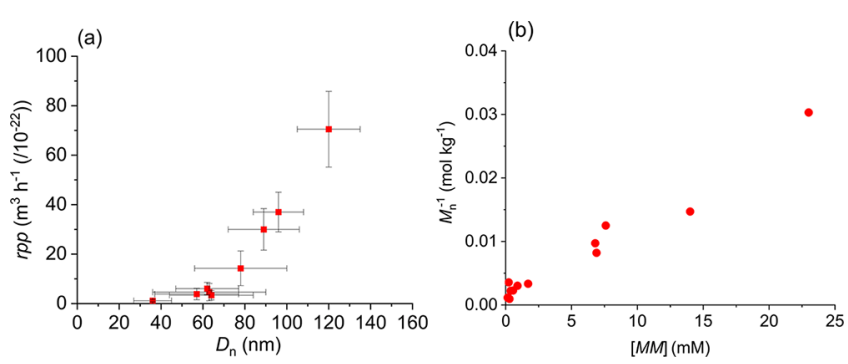

Figure 4. (a) Rate per particle versus number mean particle size, including standard error bars and (b) reciprocal of molar mass versus surfactant concentration for pMMA latexes stabilized with $\mathrm{MAA}_{n}$-co$\mathrm{LMA}_{m}$ macromonomers.

From Table 4, an apparent relation can be seen between [MM] and the molar mass $\left(M_{n}\right)$ of the final emulsion polymer. From Figure $4 b$, it is clear that an inverse proportional relation between $M_{\mathrm{n}}$ and $[\mathrm{MM}]$, irrespective of the type of the macromonomer, exists. This suggests that molar mass control is dominated by chain transfer ${ }^{43,54}$ and not by the particle number. Between the composition of the macromonomer and $D_{n}$ or $M_{n}$, no obvious relations could be found.

When comparing the latexes stabilized by 5 wt $\% \mathrm{MAA}_{n}$-co$\mathrm{BMA}_{m}$ and those by 5 wt \% $\mathrm{MAA}_{n}$-co-LMA $\mathrm{LM}_{m}$, the former latexes have in general larger particle sizes $(106-140 \mathrm{~nm})$ than the latter $(36-89 \mathrm{~nm})$, which suggests that the macromonomers with the longer hydrophobic chain segment form more easily primary particles, which finally results in more and thus smaller polymer particles. Also, the visual appearance of the $\mathrm{MAA}_{n}$-co- $\mathrm{BMA}_{m}$-stabilized latexes differ from that of the $\mathrm{MAA}_{n}-\mathrm{co}-\mathrm{LMA}_{m}$-stabilized ones: all $\mathrm{MAA}_{n}-\mathrm{co}-\mathrm{BMA}_{m}$-stabilized latexes were of type II, and some of the $\mathrm{MAA}_{n}-\mathrm{co}-\mathrm{LMA}_{m}{ }^{-}$ stabilized latexes were of type II (weakly flocculated), but most of the latexes were of type I (fluid-like), see Table 4. A more quantitative insight in the visual appearance of the latter latexes can be obtained from the results of the rheological measurements (Figures 5 and 5). In Figure 5a,b, the flow curves of the series of latexes are shown in Figure 5 a for the latexes stabilized

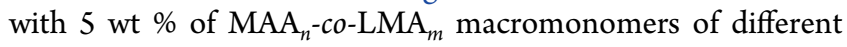
compositions and in Figure $5 \mathrm{~b}$ for the latexes stabilized by variable amounts of $\mathrm{L}_{204-18 / 189-21}$ and $\mathrm{L}_{15-2}$ macromonomers. All latexes show shear thinning, (pseudo) plastic behavior, but the viscosities at rest differ from $10^{-2} \mathrm{~Pa} \mathrm{~s}\left(5 \mathrm{~L}-\mathrm{L}_{8-3}\right.$ and $5 \mathrm{~L}-$ $\left.\mathrm{L}_{5-1}\right)$ to $10 \mathrm{~Pa} \mathrm{~s}\left(5 \mathrm{~L}-\mathrm{L}_{82-26}\right.$ and $5 \mathrm{~L}-\mathrm{L}_{15-2}$ ).

The latexes $5 \mathrm{~L}-\mathrm{L}_{82-26}$ and $2.5 \mathrm{~L}-\mathrm{L}_{204-18}$ show plastic behavior (slope in the double-log plot is -1 ), and their yield stresses were found to be 3 and $0.5 \mathrm{~Pa}$, respectively. The other latexes

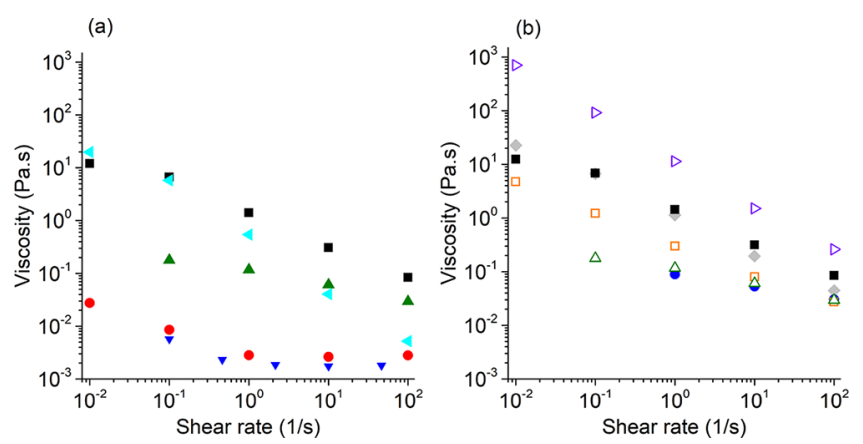

Figure 5. Viscosity of pMMA latexes (a) stabilized with 5 wt \% of $\mathrm{MAA}_{n}$-co-LMA $m$ macromonomers with different compositions: (green solid triangle) $5 \mathrm{~L}-\mathrm{L}_{189-21}$; (cyan solid left-pointing triangle) $5 \mathrm{~L}-\mathrm{L}_{82-26}$; (black solid square) $5 \mathrm{~L}-\mathrm{L}_{15-2}$; (red solid circle) $5 \mathrm{~L}-\mathrm{L}_{8-3}$; (blue solid inverted triangle) $5 \mathrm{~L}-\mathrm{L}_{5-1}$; (b) stabilized with variable amounts of macromonomer: (yellow open square) $1.3 \mathrm{~L}-\mathrm{L}_{204-18}(1.3 \mathrm{wt} \%)$; (purple open right-pointing triangle) 2.5L- $\mathrm{L}_{204-18}(2.5 \mathrm{wt} \%$ ); (green open triangle) $5 \mathrm{~L}-\mathrm{L}_{189-21}(5 \mathrm{wt} \%)$; (gray solid diamond) $1.3 \mathrm{~L}-\mathrm{L}_{15-2}$ (1.3 wt \%); (black solid square) $5 \mathrm{~L}-\mathrm{L}_{15-2}(5 \mathrm{wt} \%)$; (blue solid circle) $10 \mathrm{~L}_{-} \mathrm{L}_{15-2}(10 \mathrm{wt} \%)$.

behaved pseudo-plastic (slope in the double-log plot between -0.3 and -1 ), with estimated yield stresses between 0.01 and $0.09 \mathrm{~Pa}$. At high shear rates, the viscosities of most latexes do not level off, suggesting that even higher shear rates are needed to break up the internal network structure. ${ }^{7,48}$ Only for the latexes stabilized with the macromonomers with the lowest $\mathrm{DP}_{\mathrm{n}}\left(5 \mathrm{~L}_{-} \mathrm{L}_{8-3}\right.$ and $\left.5 \mathrm{~L}-\mathrm{L}_{5-1}\right)$, the viscosities level off at a shear rate above $1 \mathrm{~s}^{-1}$ and at a low value.

These results are consistent with the results of the dynamic time sweep series (Figure 6). In all cases, the existing network is destroyed at high shear rates but is immediately restored at rest. In Figure 6a, the dynamic time sweep series of the latexes stabilized with 5 wt \% macromonomer is shown. Almost all latexes show viscous behavior $\left(G^{\prime \prime} \geq G^{\prime}\right)$; only the latex stabilized with 5 wt $\% 5 \mathrm{~L}-\mathrm{L}_{82-26}$ behaved like a soft solid. In Figure $6 \mathrm{~b}$, the results are shown for the latexes stabilized with variable amounts of the macromonomers $L_{204-18 / 189-21}$ and $\mathrm{L}_{15-2}$. In the case of $\mathrm{L}_{15-2}$, the network formation and viscosity decrease with the increasing amount of macromonomeric surfactant, which can be expected when the interparticle repulsion forces between the particles increase. In the case of the large macromonomer $\mathrm{L}_{204-18 / 189-21}$, different effects can be seen with the increasing macromonomer concentration: at a low concentration $([\mathrm{MM}]=0.14,0.35 \mathrm{mM})$, a weak network consisting of flocs is formed, probably by bridging of the hydrophobic groups between the different particles, so a high $\eta_{0}$ and $\tau_{0}$ are measured; this network is, however, readily affected by shear (Figure 5b). At a high macromonomer concentration $([\mathrm{MM}]=0.56 \mathrm{mM})$, the viscosity decreases by the increase of electrostatic forces, caused by the increasing MAA concentration $([\mathrm{MAA}]=24,57$, and $106 \mathrm{mM}$, respectively).

In earlier work, ${ }^{41}$ we also synthesized block and graft MAAcontaining copolymers and used these as stabilizers in emulsion polymerization. If we compare those results with the results of this work, we can carefully conclude that the stabilizers with the least hydrophobic comonomer, MMA $\left(\mathrm{MAA}_{n}\right.$-co-MMA $\left.\mathrm{MM}_{m}\right)$, give the least stable latexes. All other types of stabilizers (containing BMA, LMA, or BA) provide stable, shear thinning latexes, albeit with different viscosities at rest and high shear. In several industrial processes, it is important 

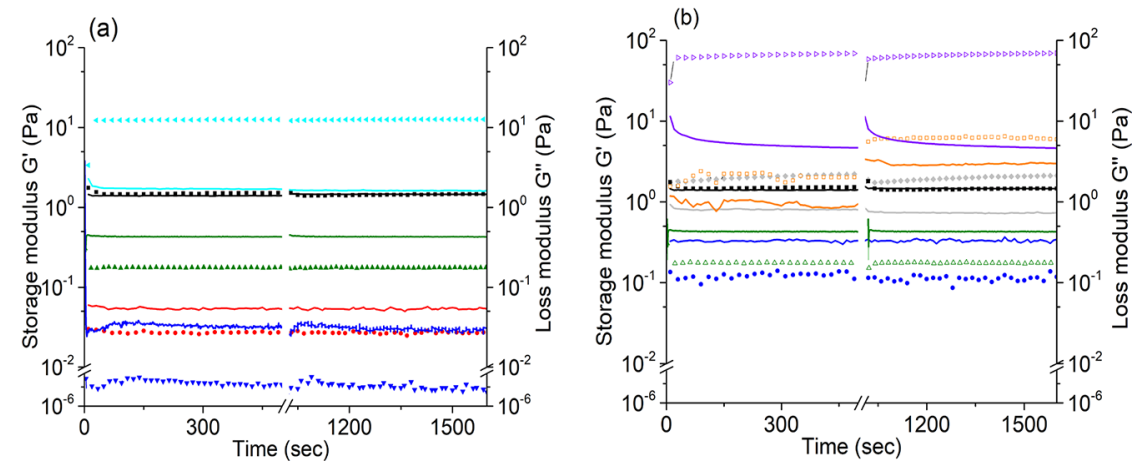

Figure 6. Storage modulus G' (symbols, number of points reduced for visibility) and loss modulus G' (solid lines) as a function of time; strain = $0.001, \omega=6.3 \mathrm{rad} / \mathrm{s}$; at $1000 \mathrm{~s}$, the sample was agitated at a shear rate of $100 \mathrm{~s}^{-1}$ for $100 \mathrm{~s}$ : (a) pMMA latex stabilized with 5 wt $\%$ of $\mathrm{MAA}_{n}-c 0$ -

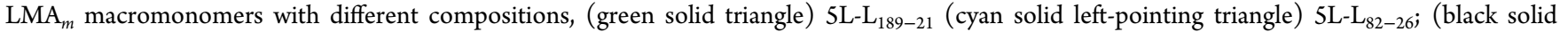
square) $5 \mathrm{~L}_{-\mathrm{L}_{15-2}}$; (red solid circle) $5 \mathrm{~L}-\mathrm{L}_{8-3}$; (blue solid inverted triangle) $5 \mathrm{~L}-\mathrm{L}_{5-1}$; (b) pMMA latex stabilized with variable amounts of macromonomer, (yellow open square) 1.3L- $\mathrm{L}_{204-18}(1.3 \mathrm{wt} \%)$; (purple open right-pointing triangle) 2.5L- $\mathrm{L}_{204-18}(2.5 \mathrm{wt} \%)$; (lime open triangle) $5 \mathrm{~L}-\mathrm{L}_{189-21}$ (5 wt \%; (gray solid diamond) $1.3 \mathrm{~L}-\mathrm{L}_{15-2}(1.3 \mathrm{wt} \%)$; (black solid triangle) $5 \mathrm{~L}-\mathrm{L}_{15-2}$ (5 wt \%); (blue solid circle) $10 \mathrm{~L}-\mathrm{L}_{15-2}(10 \mathrm{wt} \%$ ).

to control the degree of internal network formation. In coating applications, for example, weak, reversible flocculation with minor network formation will provide the best results: a low viscosity latex is obtained when shear is applied (during brushing), while at low shear, sagging is prevented by the presence of the minor network. ${ }^{50,55}$ The optimal yield stress for a final coating lies between 0.4 and $1 \mathrm{~Pa}$ with an optimal viscosity of $0.1-0.3 \mathrm{~Pa} \cdot \mathrm{s}$ at high shear rates. ${ }^{56}$ With all types of our synthesized stabilizers, latexes could be obtained, which are suitable to be used in a formulation to match these requirements.

In Figure 7, the particle diameters of the synthesized latexes versus the concentration MAA units in the surfactant are

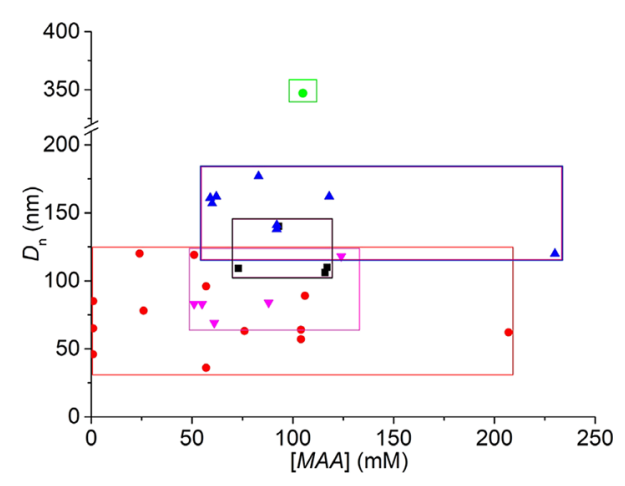

Figure 7. Particle diameter of synthesized latexes versus concentration MAA units (from the surfactant) in the emulsion polymerization: (lime solid circle) statistical $\mathrm{MAA}_{n}$-co-MMA $\mathrm{MM}_{m}$ (black solid square) statistical $\mathrm{MAA}_{n}$-co-BMA $\mathrm{BM}_{m}$ ( red solid circle) statistical $\mathrm{MAA}_{n}$-co$\mathrm{LMA}_{m}$ (blue solid triangle) block $\mathrm{MAA}_{n}-\mathrm{co}-\mathrm{MMA}_{m}{ }^{41}$ and (lavender solid inverted triangle) graft $\mathrm{MAA}_{n}-c o-\mathrm{BA}_{m} \cdot{ }^{41}$ The results for each type of surfactant are enclosed by a rectangle.

compared for the surfactants of the current and our earlier study. ${ }^{41}$ Although not very strong, there seems to be a correlation between the particle diameter of the latex and the length of the tail of the hydrophobic group (i.e., methyl, butyl, or lauryl) for the macromonomeric surfactants. The larger the hydrophobic group, the smaller the diameter of the latex particles. The latexes synthesized with the graft $\mathrm{MAA}_{n}-c o-\mathrm{BA}_{m}$ polymeric surfactants ${ }^{41}$ show a behavior more or less similar to those synthesized using the lauryl-containing macromonomeric surfactant, probably due to the presence of the grafted polymeric tails. The length of the hydrophobic group of the surfactant seems to be of more importance than the number of hydrophilic groups present. In general, for these macromonomeric stabilizers, it is found that using macromonomers with larger hydrophobic groups results in latexes with smaller particle sizes.

\section{CONCLUSIONS}

Different statistical comacromonomers containing MAA and MMA, BMA, or LMA were synthesized by CCTP, and those containing BMA and LMA were shown to be good stabilizers in the emulsion polymerization of MMA. The large hydrophobic groups of LMA in the macromonomer provide fast and easy particle nucleation, giving rise to smaller particles as compared to BMA-containing macromonomers. Almost independent of the ratio between hydrophobic and hydrophilic units and the length of the macromonomer, stable latexes could be prepared. In many cases, it was possible to affect the particle diameter and the molar mass by changing the amount of stabilizer and the composition, without loss of stability. The composition and concentration of the macromonomer appear to have a large influence on the interparticle forces in the latex, affecting the microstructure and thus the rheological behavior of the latex, e.g., the viscosity and flow properties. Most of the latexes synthesized with these statistical comacromonomers show shear thinning behavior with a viscosity at high shear rates below $0.1 \mathrm{~Pa}$ s and no aggregation, similar to binders used for coating formulations. In addition, taking into account the easier synthesis route for the statistical macromonomers (onepot synthesis), the synthesis of pMMA latexes with these statistical macromonomers is very promising.

\section{ASSOCIATED CONTENT}

\section{Supporting Information}

The Supporting Information is available free of charge at https://pubs.acs.org/doi/10.1021/acsapm.1c00715.

Additional experimental details about the polymerizations and characterizations of synthesized macromonomers and latexes: NMR, MALDI-ToF MS, SEC, DLS, SEM, and rheology (PDF) 


\section{AUTHOR INFORMATION}

\section{Corresponding Author}

Johan P.A. Heuts - Department of Chemical Engineering \& Chemistry and Institute for Complex Molecular Systems, Eindhoven University of Technology, 5600 MB Eindhoven, The Netherlands; ㅇo이.org/0000-0002-9505-8242; Email: j.p.a.heuts@tue.nl

\section{Author}

Ingeborg Schreur-Piet - Department of Chemical Engineering \& Chemistry and Institute for Complex Molecular Systems, Eindhoven University of Technology, 5600 MB Eindhoven, The Netherlands

Complete contact information is available at:

https://pubs.acs.org/10.1021/acsapm.1c00715

\section{Notes}

The authors declare no competing financial interest.

\section{ACKNOWLEDGMENTS}

We gratefully acknowledge financial support by the Stichting Emulsion Polymerization. Patricia Marín is gratefully acknowledged for help with the NMR measurements. Electron microscopy was performed at the Center for Multiscale Electron Microscopy at Eindhoven University of Technology.

\section{REFERENCES}

(1) Urban, D.; Takamura, K., Eds.; Polymer dispersions and their industrial applications. Wiley-VCH: Weinheim, 2002.

(2) Elaissari, A. Colloidal polymers: synthesis and characterization. Marcel Dekker: New York, 2003.

(3) Lovell, P.A.; El-Aasser, M.S., Eds.; Emulsion polymerization and emulsion polymers. Wiley: Chichester, 1997.

(4) Li, J.; Fan, J.; Cao, R.; Zhang, Z.; Du, J.; Peng, X. Encapsulated Dye/Polymer Nanoparticles Prepared via Mini emulsion Polymerization for Inkjet Printing. ACS Omega 2018, 3, 7380-7387.

(5) Zhang, X.; Fu, H.; Huang, H.; Chen, H. Influence of carboxyl groups on the particle size and rheological properties of polyacrylate latices. J. Wuhan Univ. Technol. Mat. Sci. Ed. 2010, 25, 492-498.

(6) Wang, H.; Li, B.; Fei, G.; Shen, Y.; Zhu, K. Phase inversion, formation and stability mechanism of poly(urethane-acrylate) nanoemulsions based on block-copolymer surfmer. Appl. Surf. Sci. 2018, 456, 307-317.

(7) Russell, W.B.; Saville, D.A.; Schowater, W.R. Colloidal dispersions; Batchelor, G.K., Ed.; Cambridge University Press: Cambridge, 1991.

(8) Charmeau, J. Y.; Berthet, R.; Gringreau, C.; Holl, Y.; Kientz, E. Effects of film structure on mechanical and adhesion properties of latex films. Int. J. Adhes. Adhes. 1997, 17, 169-176.

(9) Tobing, S. D.; Klein, A. Molecular parameters and their relation to the adhesive performance of emulsion acrylic pressure-sensitive adhesives. II. Effect of crosslinking. J. Appl. Polym. Sci. 2001, 79, $2558-2564$.

(10) Butler, L. N.; Fellows, C. M.; Gilbert, R. G. Effect of surfactant systems on the water sensitivity of latex films. J. Appl. Polym. Sci. 2004, 92, 1813-1823.

(11) Aramendia, E.; Barandiaran, M. J.; Grade, J.; Blease, T.; Asua, J. M. Improving water sensitivity in acrylic films using surfmers. Langmuir 2005, 21, 1428-1435.

(12) Luo, Z.; Huang, H. Glass-transition temperature of a polyacrylate latex film and its water whitening resistance. J. Appl. Polym. Sci. 2020, 137, 48361.

(13) Aguirreurreta, Z.; Dimmer, J. A.; Willerich, I.; de la Cal, J. C.; Leiza, J. R. Water whitening reduction in waterborne pressuresensitive adhesives produced with polymerizable surfactants. Macromol. Mater. Eng. 2015, 300, 925-936.
(14) Aguirreurreta, Z.; de la Cal, J. C.; Leiza, J. R. Preparation of high solids content waterborne acrylic coatings using polymerizable surfactants to improve water sensitivity. Prog. Org. Coat. 2017, 112, 200-209.

(15) Steward, P. A.; Hearn, J.; Wilkinson, M. C. An overview of polymer latex film formation and properties. Adv. Colloid Interface Sci. 2000, 86, 195-267.

(16) Guyot, A. Advances in reactive surfactants. Adv. Colloid Interface Sci. 2004, 108-109, 3-22.

(17) Aramendia, E.; Mallégol, J.; Jeynes, C.; Barandiaran, M. J.; Keddie, J. L.; Asua, J. M. Distribution of surfactants near acrylic latex film surfaces: A comparison of conventional and reactive surfactants (Surfmers). Langmuir 2003, 19, 3212-3221.

(18) Guyot, A.; Tauer, K. Reactive surfactants in emulsion polymerization. Adv. Polym. Sci. 1994, 111, 43-65.

(19) Vidal, F.; Guillot, J.; Guyot, A. Surfactants with transfer agent properties (transurfs) in styrene emulsion polymerization. Colloid Polym. Sci. 1995, 273, 999-1007.

(20) Lee, W. H.; Booth, J. R.; Bon, S. A. F. On Particle Size Distributions in Catalytic Chain Transfer Emulsion Polymerization: Chain-Extension and the Use of Derived Macromonomers as Reactive Surfactants in Emulsion Polymerization. Biomacromolecules 2020, 21 , 4599-4614.

(21) Tauer, K. In Advanced Polymer Nanoparticles: Synthesis and Surface Modifications; V., Mittal, Ed; CRC Press: Boca Raton, 2010, pp. 3299-3214.

(22) Gregory, J. Polymer adsorption and flocculation in sheared suspensions. Colloids Surf. 1988, 31, 231-253.

(23) Asua, J. M.; Schoonbrood, H. A. S. Reactive surfactants in heterophase polymerization. Acta Polym. 1998, 49, 671-686.

(24) Dimonie, V. L.; Sudol, E. D.; El-Aasser, M. S. Role of Surfactants in Emulsion Polymerization Polymers by design. Rev. Chim. 2008, 59, 1218-1221.

(25) Heuts, J. P. A.; Smeets, N. M. B. Catalytic chain transfer and its derived macromonomers. Polym. Chem. 2011, 2, 2407-2423.

(26) Gridnev, A. A.; Ittel, S. D. Catalytic chain transfer in free-radical polymerizations. Chem. Rev. 2001, 101, 3611-3660.

(27) Krstina, J.; Moad, G.; Rizzardo, E.; Winzor, C. L.; Berge, C. T.; Fryd, M. Narrow Polydispersity Block Copolymers by Free-Radical Polymerization in the Presence of Macromonomers. Macromolecules 1995, 28, 5381-5385.

(28) Krstina, J.; Moad, C. L.; Moad, G.; Rizzardo, E.; Berge, C. T.; Fryd, M. A new form of controlled growth free radical polymerization. Macromol. Symp. 1996, 111, 13-23.

(29) Yamada, B.; Oku, F.; Harada, T. Substituted propenyl end groups as reactive intermediates in radical polymerization. J. Polym. Sci., Part A: Polym. Chem. 2003, 41, 645-654.

(30) Schreur-Piet, I.; Heuts, J. P. A. In situ stabilizer formation from methacrylic acid macromonomers in emulsion polymerization. Polym. Chem. 2017, 8, 6654-6664.

(31) Patias, G.; Wemyss, A. M.; Efstathiou, S.; Town, J. S.; Atkins, C. J.; Shegiwal, A.; Whitfield, R.; Haddleton, D. M. Controlled synthesis of methacrylate and acrylate diblock copolymers: Via end-capping using CCTP and FRP. Polym. Chem. 2019, 10, 6447-6455.

(32) Shegiwal, A.; Wemyss, A. M.; Schellekens, M. A. J.; de Bont, J.; Town, J.; Liarou, E.; Patias, G.; Atkins, C. J.; Haddleton, D. M. Exploiting catalytic chain transfer polymerization for the synthesis of carboxylated latexes via sulfur-free RAFT. J. Polym. Sci., Part A: Polym. Chem. 2019, 57, e1-e9.

(33) Chen, L.; Yan, L.; Li, Q.; Wang, C.; Chen, S. Controllable synthesis of new polymerizable macrosurfactants via CCTP and RAFT techniques and investigation of their performance in emulsion polymerization. Langmuir 2010, 26, 1724-1733.

(34) Nurumbetov, G.; Engelis, N.; Godfrey, J.; Hand, R.; Anastasaki, A.; Simula, A.; Nikolaou, V.; Haddleton, D. M. Methacrylic block copolymers by sulfur free RAFT (SF RAFT) free radical emulsion polymerisation. Polym. Chem. 2017, 8, 1084-1094.

(35) Shegiwal, A.; Wemyss, A. M.; Liarou, E.; Town, J.; Patias, G.; Atkins, C. J.; Marathianos, A.; Lester, D. W.; Efstathiou, S.; 
Haddleton, D. M. Polymerisable surfactants for polymethacrylates using catalytic chain transfer polymerisation (CCTP) combined with sulfur free-RAFT in emulsion polymerisation. Eur. Polym. J. 2020, 125, No. 109491.

(36) Khor, S. Y.; Quinn, J. F.; Whittaker, M. R.; Truong, N. P.; Davis, T. P. Controlling Nanomaterial Size and Shape for Biomedical Applications via Polymerization-Induced Self-Assembly. Macromol. Rapid Commun. 2019, 40, No. 1800438.

(37) Charleux, B.; Delaittre, G.; Rieger, J.; D’Agosto, F. Polymerization-induced self-assembly: from soluble macromolecules to block copolymer nano-objects in one step. Macromolecules 2012, 45, 67536765.

(38) Lotierzo, A.; Schofield, R. M.; Bon, S. A. F. Towards sulfur-free RAFT polymerization induced self-assembly. ACS Macro Lett. 2017, 6, 1438-1443.

(39) D’Agosto, F.; Rieger, J.; Lansalot, M. RAFT-Mediated Polymerization-Induced Self-Assembly. Angew. Chem. Int. Ed. 2020, 59, 8368-8392.

(40) Marathianos, A.; Wemyss, A. M.; Liarou, E.; Jones, J. R.; Shegiwal, A.; Town, J. S.; Lester, D.; Li, Y.; Haddleton, D. M. Controlling the particle size in surfactant-free latexes from $\omega$-propenyl oligomers obtained through catalytic chain transfer polymerization. ACS Appl. Polym. Mater. 2021, 3, 3185-3196.

(41) Schreur-Piet, I.; van Herk, A. M.; Laven, J.; Heuts, J. P. A. Synthesis and rheological characterization of latexes stabilized by methacrylic acid containing macromonomers. Ind. Eng. Chem. Res. 2019, 58, 21105-21117.

(42) Bakac, A.; Brynildson, M. E.; Espenson, J. H. Characterization of the structure, properties, and reactivity of a cobalt(II) macrocyclic complex. Inorg. Chem. 1986, 25, 4108-4114.

(43) Muratore, L. M.; Heuts, J. P. A.; Davis, T. P. Synthesis of 3-[tris (trimethylsilyloxy) silyl] propyl methacrylate macromers using catalytic chain transfer polymerization: a kinetic and mechanistic study. Macromol. Chem. Phys. 2000, 201, 985-994.

(44) Staal, B.B.P. Characterization of (co)polymers by MALDI-ToF MS, PhD Thesis, University of Technology Eindhoven, 2005.

(45) Willemse, R.X.E. New insights into free-radical (co)polymerization kinetics, PhD Thesis, University of Technology Eindhoven, 2005.

(46) International Standard ISO13321. Methods for Determination of Particle Size Distribution Part 8: Photon Correlation Spectroscopy. International Organisation for Standardisation (ISO), 1996.

(47) International Standard ISO22412. Particle Size Analysis Dynamic Light Scattering. International Organisation for Standardisation (ISO), 2008.

(48) Everett, D. Basic principles of colloid science. R.S.C. Whitstable Litho Ltd: Whitstable, 1988.

(49) Trappe, V.; Sandkühler, P. Colloidal gels-low-density disordered solid-like states. Curr. Opin. Colloid Interface Sci. 2004, 8, 494-500.

(50) Mewis, J.; Wagner, N. J.. Colloidal Suspension Rheology; Cambridge Series in Chemical Engineering. Cambridge University Press: Cambridge, 2011, DOI: 10.1017/CBO9780511977978.

(51) Babick, F. Suspensions of colloidal particles and aggregates; Particle technology series, Vol. 20, Valverde Millan, J.M., Ed; Springer Int. Publ. AG: Switzerland, 2016.

(52) Casey, B. S.; Morrison, B. R.; Maxwell, I. A.; Gilbert, R. G.; Napper, D. H. Free radical exit in emulsion polymerization. I. Theoretical model. J. Polym. Sci., Part A: Polym. Chem. 1994, 32, 605630.

(53) Thickett, S. C.; Gilbert, R. G. Emulsion polymerization: State of the art in kinetics and mechanisms. Polymer 2007, 48, 6965-6991.

(54) Mayo, F. R. Chain Transfer in the Polymerization of Styrene: The Reaction of Solvents with Free Radicals. J. Am. Chem. Soc. 1943, 65, 2324-2329.

(55) Koleske, J. V., Ed.; Paint and coatings testing manual, 15th edition. ASTM Manual Series: Bridgeport, 2012.

(56) Patton, T.C. Paint flow and pigment dispersion, a rheological approach to coating and ink technology, 2nd edition. John Wiley \& Sons: New York, 1979. 